University of Wollongong

Research Online

Faculty of Engineering and Information

Faculty of Engineering and Information

Sciences - Papers: Part A

Sciences

$1-1-2016$

The rheology of shear thickening fluids with various ceramic particle additives

\title{
Selim Gürgen
}

University of Wollongong, Anadolu University, selim@uow.edu.au

Weihua Li

University of Wollongong, weihuali@uow.edu.au

Melih Cemal Kushan

Eskisehir Osmangazi University

Follow this and additional works at: https://ro.uow.edu.au/eispapers

Part of the Engineering Commons, and the Science and Technology Studies Commons

Research Online is the open access institutional repository for the University of Wollongong. For further information contact the UOW Library: research-pubs@uow.edu.au 


\title{
The rheology of shear thickening fluids with various ceramic particle additives
}

\author{
Abstract \\ In this paper, shear thickening fluids (STFs) and three different types of additive particles such as silicon \\ carbide, aluminum oxide and boron carbide are presented. STFs were fabricated based on nanosize \\ fumed silica suspended in a liquid medium, polyethylene glycol at a constant concentration of $20 \mathrm{wt} \%$, \\ and then varying amounts of different types of particle additives were added. Their rheological properties \\ under various temperatures were tested using a rheometer, and the effects of silica loading on the \\ rheology of pure STF were investigated. The suspensions exhibited different systematic variations with \\ respect to the varied parameters.
}

Keywords

ceramic, particle, rheology, additives, shear, thickening, fluids, various

Disciplines

Engineering | Science and Technology Studies

Publication Details

Gurgen, S., Li, W. \& Kushan, M. Cemal. (2016). The rheology of shear thickening fluids with various ceramic particle additives. Materials and Design, 104 312-319.

This journal article is available at Research Online: https://ro.uow.edu.au/eispapers/5887 


\title{
The Rheology of Shear Thickening Fluids with Various Ceramic Particle Additives
}

\author{
Selim Gürgen ${ }^{1,2 *}$, Weihua $\mathrm{Li}^{1}$ and Melih Cemal Kuşhan ${ }^{3}$ \\ ${ }^{1}$ School of Mechanical, Materials and Mechatronic Engineering, University of Wollongong, Wollongong, \\ NSW 2522, Australia \\ ${ }^{2}$ Vocational School of Transportation, Anadolu University, Eskişehir, 26470, Turkey \\ ${ }^{3}$ Department of Mechanical Engineering, Eskişehir Osmangazi University, Eskişehir, 26480, Turkey
}

\section{*Corresponding author: Selim Gürgen}

E-mail: selimgurgen@anadolu.edu.tr

selim@uow.edu.au

\begin{abstract}
In this paper, shear thickening fluids (STFs) and three different types of additive particles such as silicon carbide, aluminum oxide and boron carbide are presented. STFs were fabricated based on nanosize fumed silica suspended in a liquid medium, polyethylene glycol at a constant concentration of $20 \mathrm{wt} \%$, and then varying amounts of different types of particle additives were added. Their rheological properties under various temperatures were tested using a rheometer, and the effects of silica loading on the rheology of pure STF were investigated. The suspensions exhibited different systematic variations with respect to the varied parameters.
\end{abstract}

Keywords: shear thickening fluid, additives, silicon carbide, aluminum oxide, boron carbide, rheology.

\section{Introduction}

Shear thickening fluid (STF) is non-Newtonian fluid with an increasing viscosity under applied stress. Hoffman [1] conducted a pilot study into the thickening mechanism of STF, and suggested that below a critical shear rate, particles in STF are in a hexagonally packed order, but beyond this point, particle formation decays such that the packed particles become disordered and aggregate. This transition from order to disorder increases in the viscosity of this suspension. After this pioneering study, STF was discussed by hydro-cluster theory which suggests that particles contact each other under high stress and cause strong hydrodynamic forces to act inside the suspension, which is why these particles aggregate into hydro-clusters that increase viscosity and cause the fluid to jam. [2], [3]. Hydro-cluster theory was verified via simulations of Stokesian dynamics by Bossis et al. [4] and computational simulations by Boersma et al. [5] and Melrose et al. [6-8].

Due to their unique characteristics, STFs have attracted attention in areas such as body armour systems, damping devices, and smart structures. Gates [9] made the first study to utilize STFs in armour systems. Early studies [10-20] focused on STF impregnated ballistic fabrics to enhance their protective performance while reducing weight. It was stated as a common point that STFs have a positive influence on the protective performance of ballistic fabrics. As a component of damping devices, STF was used in viscoelastic dampers to control the vibration of structural parts [21]. In order to absorb shock waves from 
earthquakes or severe wind conditions, structural components were combined with STF and the thickening response was adapted for damping [22]. Zhang et al. [23] studied STF filled dampers to observe the dynamic performance of these new systems. Fischer et al. [24] demonstrated the potential for integrating STFs into structures exposed to dynamic flexural deformation by controlling their vibrational response. Laun et al. [25] and Helber et al. [26] investigated the damping behavior of STFs and suggested they could be used in damping and mounting of industrial machinery. STFs have also been studied in the applications of smart structures. Chu et al. [27] verified an improvement of their thickening behavior by modifying the surface chemistry of silica particles. It was stated that controlling the rheology of colloidal suspensions provides important benefits in the application of energy absorbing materials. Hunt et al. [28] investigated how to minimise damage to controlled pulse fracturing (CPF) devices using STFs. Moreover, STFs could also be used to control the stiffness of composite structures by tailoring their rheological properties. These composite structures were said to be applicable for sports equipment, aeronautics, aerospace, consumer goods, or any other suitable field. William et al. [29] investigated STF based medical equipment to restrict the movement of shoulders, knees, elbows, ankles and hips to prevent these joints from sudden acceleration. Galindo-Rosales et al. [30] developed environmentally friendly composites such as micro-agglomerated cork sheets with a network of micro-channels filled with STF. These composites were investigated under low velocity impact where their mechanical properties exhibited a combination of the mechanical properties of micro-agglomerated cork sheets and the thickening response of STF inside the micro-channels.

Despite several studies into STF applications, there have only been limited investigations in the literature about integrating particle additives to STFs. Zhang et al. [31], [32] Li et al. [33] and Peng et al. [34] studied a combination of STFs and magnetorheological (MR) fluids; they called this new fluid magnetorheological shear thickening fluid (MRSTF), and then investigated its rheological properties. It was noted that MRSTFs have features of both fluids, but they are more like MR fluids. As well as the magnetic particles in STFs, Petel et al. [35], [36] investigated the ballistic resistance of bulk STFs, including carbide particles. According to their studies, carbide particles change the thickening behavior of the STFs while improving its ballistic resistance by increasing the density of this suspension and the dynamic material strength of the fluids. With this in mind, we decided to investigate the influence of ceramic particle additives due to their rigidity, even under loading. The effects of additives on the rheological behavior of STFs were investigated to provide some insights into the response of STFs and control the thickening behavior of these smart fluids. Systematic variations in the characteristics of STFs will help to determine where these novel suspensions may best be utilised in the engineering applications. In this study, silica based STFs were mixed with three different types of particle additives silicon carbide, aluminum oxide, and boron carbide because they are preferred for ceramic suspensions. The suspension temperature, type of additives, and amount of additives were varied to observe the influence of different parameters, and the effect of silica loading on the rheology of pure STF was also investigated. It was expected to provide new experience for STF applications with this novel approach.

\section{Experimental details}

The STF used in this study was based on fumed silica (Aerosil 90, from Evonik) which has a primary particle size of $20 \mathrm{~nm}$ and specific surface area of $90 \mathrm{~m}^{2} / \mathrm{g}$. The liquid medium was polyethylene glycol (PEG) with a molar mass of $400 \mathrm{~g} / \mathrm{mol}$ (81172, from Sigma-Aldrich). Three different types of ceramic particles, silicon carbide $(\mathrm{SiC})$, aluminum oxide $\left(\mathrm{Al}_{2} \mathrm{O}_{3}\right)$, and boron carbide $\left(\mathrm{B}_{4} \mathrm{C}\right)$, were used as additives in the STFs. The particle size and surface area of these additives were measured with Zetasizer Nano ZS 
and Autosorb 1-C analyser machines respectively. Table 1 summarises the measurements and densities of the additives, which were obtained from the suppliers. Particle size distribution of the additives is shown in Figure 1.

Table 1. Summary of the additive particles

\begin{tabular}{cccc}
\hline Additive & Average particle size $(\mu \mathrm{m})$ & Surface area $\left(\mathrm{m}^{2} / \mathrm{g}\right)$ & Density $\left(\mathrm{g} / \mathrm{cm}^{3}\right)$ \\
\hline $\mathrm{SiC}$ & 1.114 & 7.61 & 3.23 \\
$\mathrm{Al}_{2} \mathrm{O}_{3}$ & 0.978 & 6.78 & 3.97 \\
$\mathrm{~B}_{4} \mathrm{C}$ & 1.006 & 7.88 & 2.51 \\
\hline
\end{tabular}

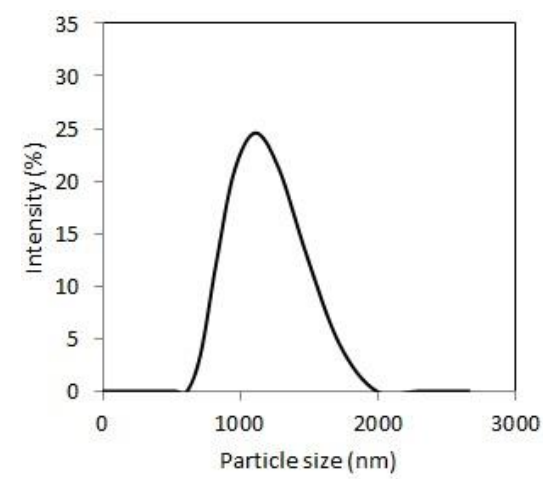

(a)

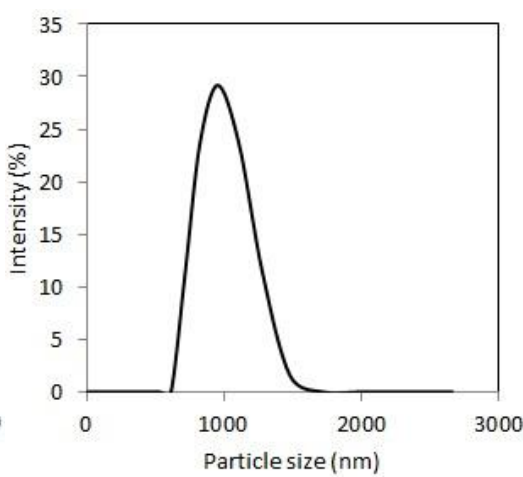

(b)

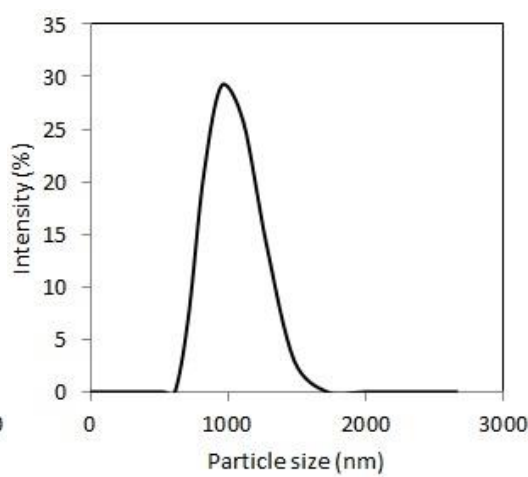

(c)

Figure 1. Particle size distribution of (a) $\mathrm{SiC}$, (b) $\mathrm{Al}_{2} \mathrm{O}_{3}$ and (c) $\mathrm{B}_{4} \mathrm{C}$ particles

In the sample preparation stage, fumed silica was mixed with PEG, as suggested in previous studies [31], [32], [34]. The silica loading was $5 \mathrm{wt} \%, 10 \mathrm{wt} \%, 15 \mathrm{wt} \%$ and $20 \mathrm{wt} \%$ to investigate the pure STFs. In the experiments of STFs with additives, silica loading was kept constant at $20 \mathrm{wt} \%$. The mixtures were blended for $40 \mathrm{~min}$. After obtaining pure STFs, additives were added to the suspensions according to the weight percentages, and then the same blending procedure was applied to the mixtures.

In this study, a three factor-three level factorial design was used to analyze how the temperature, and the type and amount of additives affected the rheological behavior of the suspensions. According to the full factorial design, $27\left(3^{3}\right)$ samples were prepared as given in Table 2.

Table 2. Design of the experiments

\begin{tabular}{ccc}
\hline \multicolumn{2}{c}{ Parameters } \\
\hline Temperature $\left({ }^{\circ} \mathrm{C}\right)$ & Type of additives & Amount of additives (wt\%) \\
\hline 20 & $\mathrm{SiC}$ & 5 \\
20 & $\mathrm{SiC}$ & 25 \\
20 & $\mathrm{SiC}$ & 45 \\
40 & $\mathrm{SiC}$ & 5 \\
\hline
\end{tabular}




\begin{tabular}{ccc}
\hline 40 & $\mathrm{SiC}$ & 25 \\
40 & $\mathrm{SiC}$ & 45 \\
60 & $\mathrm{SiC}$ & 5 \\
60 & $\mathrm{SiC}$ & 25 \\
60 & $\mathrm{SiC}$ & 45 \\
20 & $\mathrm{Al}_{2} \mathrm{O}_{3}$ & 5 \\
20 & $\mathrm{Al}_{2} \mathrm{O}_{3}$ & 25 \\
20 & $\mathrm{Al}_{2} \mathrm{O}_{3}$ & 45 \\
40 & $\mathrm{Al}_{2} \mathrm{O}_{3}$ & 5 \\
40 & $\mathrm{Al}_{2} \mathrm{O}_{3}$ & 25 \\
40 & $\mathrm{Al}_{2} \mathrm{O}_{3}$ & 45 \\
60 & $\mathrm{Al}_{2} \mathrm{O}_{3}$ & 5 \\
60 & $\mathrm{Al}_{2} \mathrm{O}_{3}$ & 25 \\
60 & $\mathrm{Al}_{2} \mathrm{O}_{3}$ & 45 \\
20 & $\mathrm{~B}_{4} \mathrm{C}$ & 5 \\
20 & $\mathrm{~B}_{4} \mathrm{C}$ & 25 \\
20 & $\mathrm{~B}_{4} \mathrm{C}$ & 45 \\
40 & $\mathrm{~B}_{4} \mathrm{C}$ & 5 \\
40 & $\mathrm{~B}_{4} \mathrm{C}$ & 25 \\
40 & $\mathrm{~B}_{4} \mathrm{C}$ & 45 \\
60 & $\mathrm{~B}_{4} \mathrm{C}$ & 5 \\
60 & $\mathrm{~B}_{4} \mathrm{C}$ & 25 \\
60 & $\mathrm{~B}_{4} \mathrm{C}$ & 45 \\
\hline
\end{tabular}

\section{Rheological testing and results}

Rheological tests were performed using an MCR 301 Anton Paar stress controlled rheometer with $20 \mathrm{~mm}$ diameter parallel plate apparatus. The gap between the plates was kept at $0.20 \mathrm{~mm}$, and the shear rate was increased from 0 to $1000 \mathrm{~s}^{-1}$ during the experiments. The suspension temperature was set with the help of a temperature control device connected to the bottom plate of the rheometer.

Before experimenting on the suspensions with additives, the effects of silica loading on pure STFs with various silica loadings were tested at a constant temperature of $20^{\circ} \mathrm{C}$. Figure 2 shows the rheological curves of pure STFs with different silica loadings, which indicate that silica loading has four main influences on the characteristics of the STFs. First, the viscosity profile of the STF increases as the silica loading increases, which means the viscosity curve of the STF shifted upward on the graph by increasing the silica loading. Second, the critical shear rate at which shear thickening begins, decreases as the silica loading increases. Third, the formation is thickened fast if the silica loading expands in the STF. This can be also explained as the difference between the critical shear rate and the shear rate at the maximum viscosity after thickening, which decreases as the silica loading increases. Finally, the thickening ratio $(T R)$ which is defined in Equation 1, increases when the silica loading expands in the suspension. The rheological curves show that the effects of silica loading on the thickening of the STFs are consistent with the results stated in previous studies [17], [18], [37], [38].

$$
T R=\frac{\eta_{\max }}{\eta_{c r}}
$$


$\eta_{\max }$ : Maximum viscosity of the suspension beyond the thickening point

$\eta_{c r}:$ Viscosity of the suspension at the critical shear rate

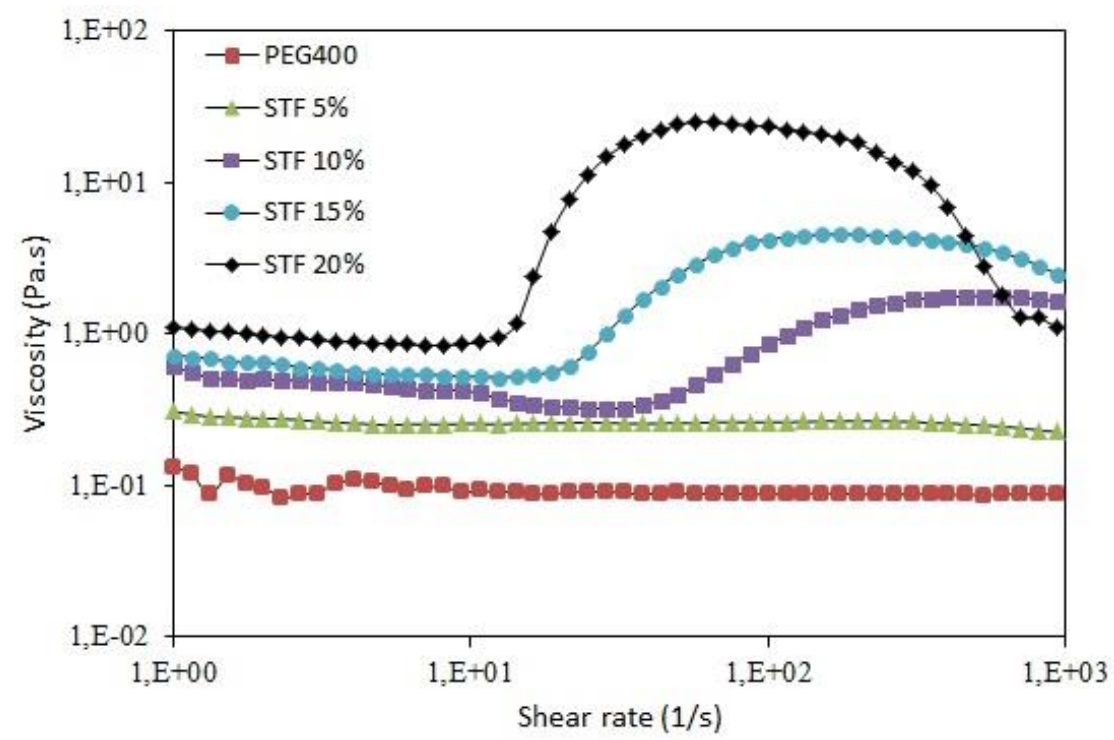

Figure 2. Rheological behavior of pure STFs including various silica loadings

\subsection{Effects on viscosity profile}

The rheological results indicated that the additives enhanced the viscosity profile of the suspensions in a similar manner, and to illustrate this effect, the rheological curves of the suspensions with different additives are shown in Figure 3. Note that the viscosity profile increases as the amount of additives in the suspension increases. In denser suspensions, solid particles exhibit stronger inter-particle adhesion and thus the viscosity of the fluid increases [39]; this is verified by the rheological measurements of STFs with various additives taken in earlier studies [31], [32], [35]. In fact the volume fraction of the particles becomes the main topic at this point. Unlike these other types of additives, $\mathrm{B}_{4} \mathrm{C}$ particles enhance the viscosity profile of the suspension much better. It is known that additive densities differ from each other, so the volume fraction of the additives varies for each three-level mass fraction of the additives in the STFs. This is why $\mathrm{B}_{4} \mathrm{C}$ particles occupy the largest volume in the suspensions; their density is lower than the other additives for each level of additive amounts. This indicates that the increase in the volumetric concentration of solid particles in the suspension contributes to the growth of the viscosity profile. Table 3 summarizes the volume fraction of the additives for the corresponding mass fractions. On the other side, temperature is another parameter that has an intense effect on the viscosity profile of STFs. The experiments revealed that increasing the temperature reduces the viscosity profile, and this trend is valid for each suspension, regardless of the type of additive. This reduction in the viscosity profile is due to the inter-particle adhesive forces becoming weaker due to the elevated temperature [40], [41]. To illustrate how the temperature influences the viscosity profile, the rheological curves of the STFs with $25 \mathrm{wt} \%$ of $\mathrm{Al}_{2} \mathrm{O}_{3}$ particles at different temperatures are shown in Figure 4. 


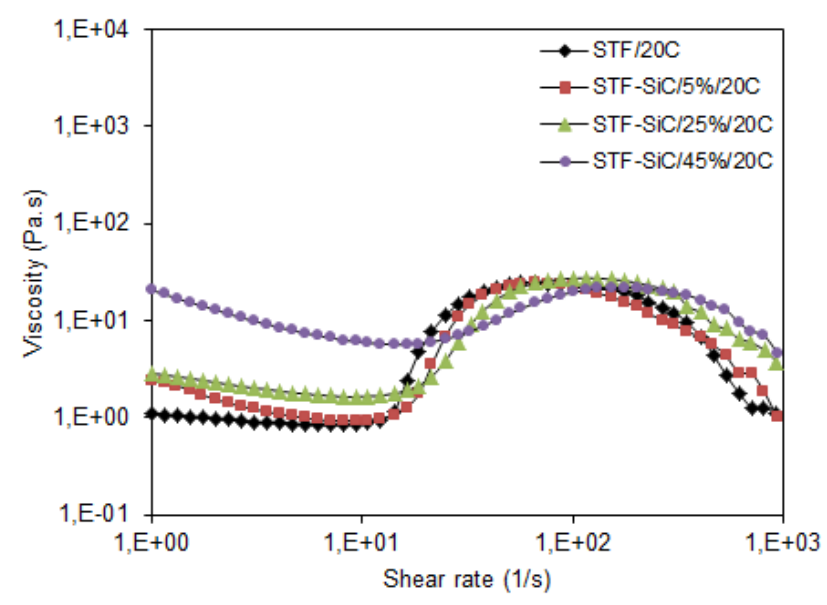

(a)

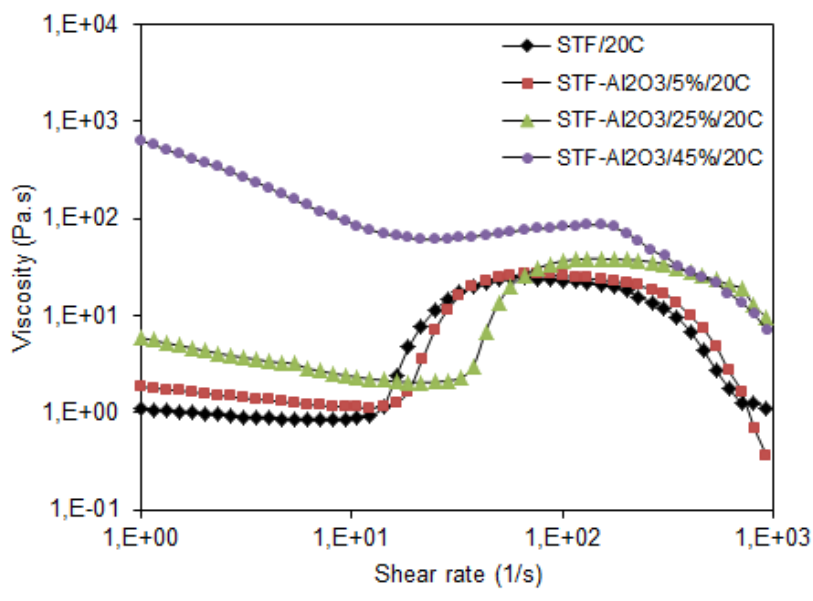

(b)

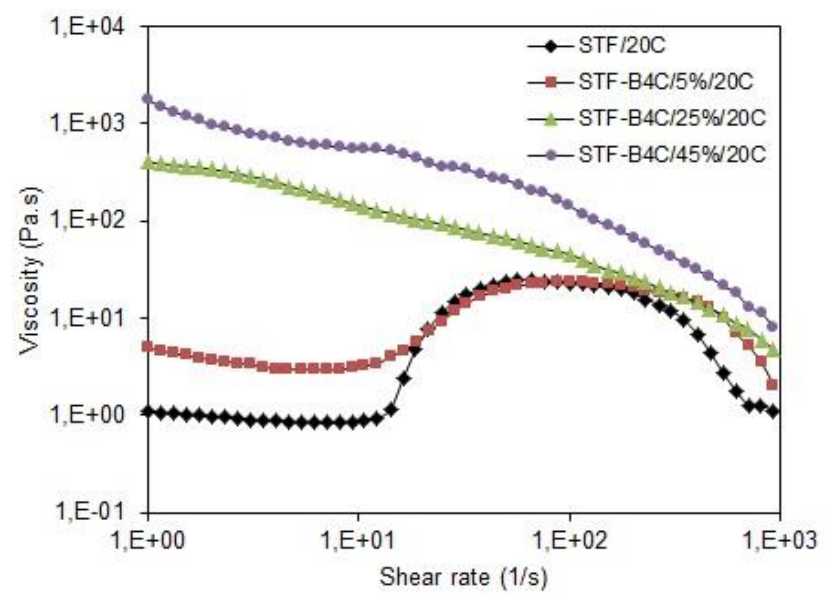

(c)

Figure 3. Rheological curves of the STFs with (a) $\mathrm{SiC}$, (b) $\mathrm{Al}_{2} \mathrm{O}_{3}$ and (c) $\mathrm{B}_{4} \mathrm{C}$ particles at $20^{\circ} \mathrm{C}$

Table 3. Volume fraction of the additives for the corresponding mass fractions

\begin{tabular}{cccc}
\hline $\begin{array}{c}\text { Amount of additives } \\
(\mathrm{wt} \%)\end{array}$ & $\mathrm{SiC}$ in STF (vol\%) & $\mathrm{Al}_{2} \mathrm{O}_{3}$ in STF (vol\%) & $\mathrm{B}_{4} \mathrm{C}$ in STF (vol\%) \\
\hline 5 & 1.98 & 1.61 & 2.53 \\
25 & 11.43 & 9.50 & 14.24 \\
45 & 24.07 & 20.51 & 28.97 \\
\hline
\end{tabular}




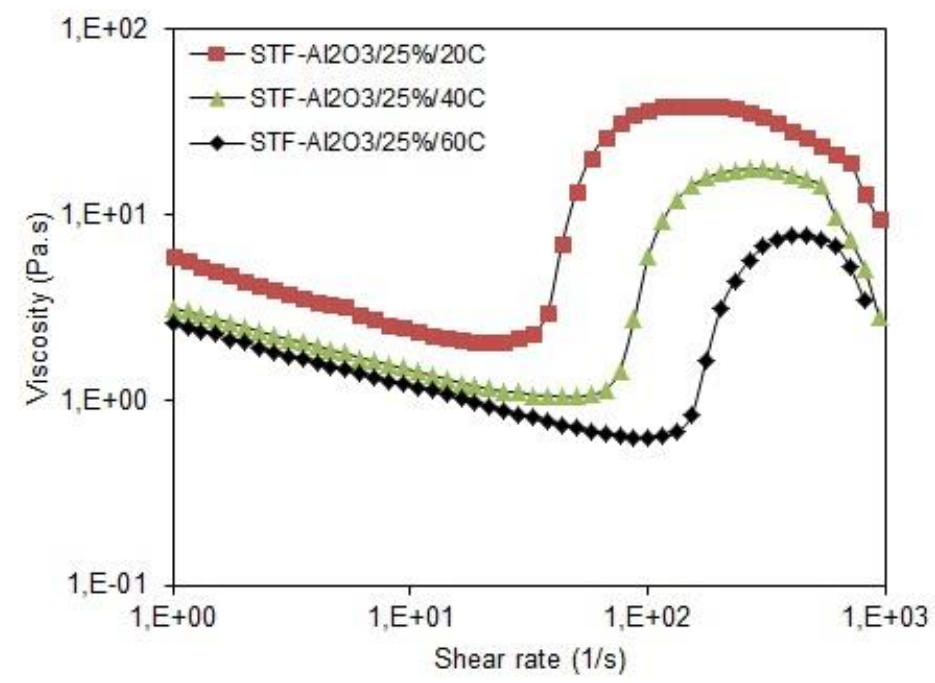

Figure 4. Rheological curves of the STFs with $25 \mathrm{wt} \%$ amount of $\mathrm{Al}_{2} \mathrm{O}_{3}$ particles at different temperatures

\subsection{Effects on critical shear rate}

Figure 5 shows the critical shear rates of the STFs, including different additives and amounts at various temperatures. Since the suspensions with $25 \mathrm{wt} \%(14.24 \mathrm{vol} \%)$ and $45 \mathrm{wt} \%$ (28.97vol\%) loadings of $\mathrm{B}_{4} \mathrm{C}$ particles did not exhibit thickening, the critical shear rates of these suspensions could not be added to the $\mathrm{B}_{4} \mathrm{C}$ chart. These suspensions only displayed shear thinning behavior for each temperature level. According to early studies [2], [18], [42], thickening gradually vanishes as the silica loading in the suspension decreases, in fact, the inclusion of additives deducts the volume fraction of the silica from the suspension, thereby adversely affecting the thickening mechanism. It is therefore possible that the volume fraction of silica falls below the effective concentration, thus triggering thickening for the suspension with $25 \mathrm{wt} \%(14.24 \mathrm{vol} \%)$ loading of $\mathrm{B}_{4} \mathrm{C}$ particles. It is also clear that the temperature influences the critical shear rate of the STFs due to enhanced inter-particle repulsive forces inside the suspension at elevated temperatures. Therefore, in order to form hydro-clusters, the STFs require stronger hydrodynamic interactions that overwhelm the inter-particle repulsive forces when the critical shear rate reaches higher values [41], [43], [44]. As a result, the critical shear rate of the STFs, including additives, increases as the temperature increases, which is similar to pure STFs. However, STFs with higher amounts of additives are more prone to increase the critical shear rates. This influence is systematically observed in the STFs with $\mathrm{Al}_{2} \mathrm{O}_{3}$ particles for each temperature level, but lower loadings of $\mathrm{SiC}$ particles do not contribute to this trend, the fact remains that heavy SiC loadings clearly increase the critical shear rate. In fact, the critical shear rate decreases as the silica loading increases in the suspension due to enough silica particles in the medium to form hydro-clusters, even though the shear rate is at lower levels [44], [45]. Unlike silica, the additives do not contribute to the thickening mechanism because they are not constitutive particles for the STFs. According to Petel et al. [35], [36], suspensions of ethylene glycol and SiC particles exhibit shear thinning behavior rather than thickening. For this reason, and the findings will be described in further paragraphs, additive particles negatively influence the thickening behavior of STFs. Therefore, it is expected that the critical shear rate increases as the amount of additives increase in the suspension. Although the results partially satisfy this expectation, there is no certain trend over the amount of additives. 


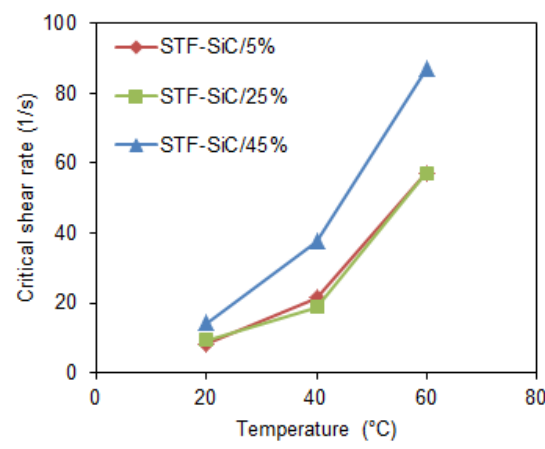

(a)

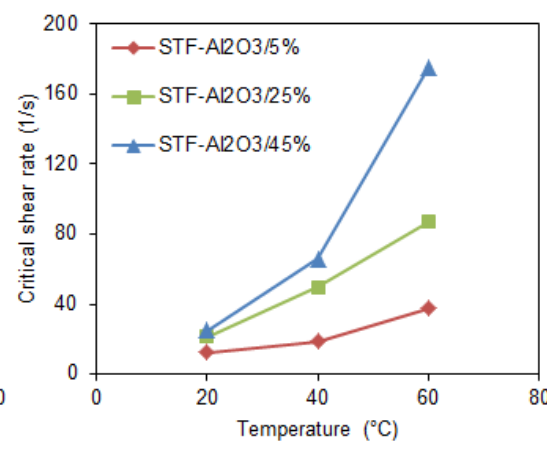

(b)

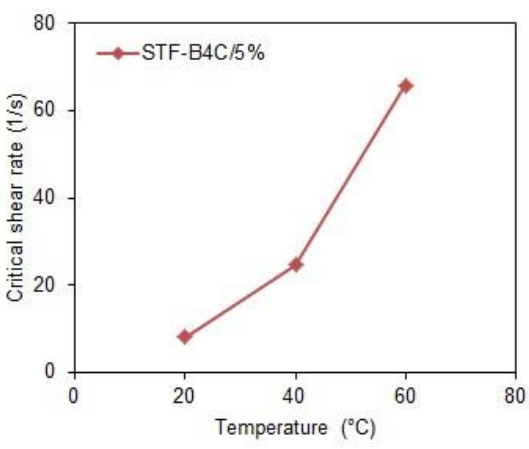

(c)

Figure 5. Critical shear rate of the $\mathrm{STF}$ with (a) $\mathrm{SiC}$, (b) $\mathrm{Al}_{2} \mathrm{O}_{3}$ and (c) $\mathrm{B}_{4} \mathrm{C}$ particles at various temperatures

\subsection{Effects on thickening period}

The thickening period is defined as the difference between the critical shear rate and the shear rate at maximum viscosity after the thickening point. Figure 6 shows the thickening periods of the STFs with various additives and amounts at different temperatures. The graphs show that the thickening period increases as the temperature increases. Similarly, the thickening period is directly proportional to the amount of additives. According to the early studies [31], [32], additives weaken the thickening behavior of STFs so thickening is retarded to higher shear rates. Distributing the additives in the STFs causes the interstitial additive particles between the silica particles, thereby hindering the formation of hydroclusters. Raghavan et al. [42] stated that hydro-clusters forming during thickening are elongated structures not spherical aggregations, while Bossis et al. [4] suggested that hydrodynamic stresses are proportional to the cube of the larger dimension of the clusters, which means that elongated clusters contribute much more to the thickening behavior than spherical ones. Moreover, the additive particles restrict the hydroclusters from extending during thickening, so they are much smaller in size. In other words the additive particles can be defined as barriers against the elongation of hydro-cluster networks during cluster formation.

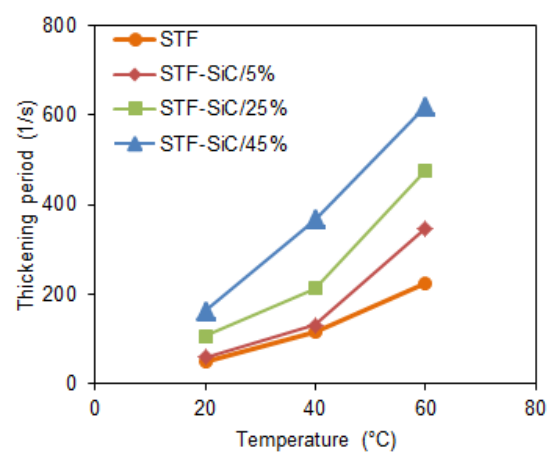

(a)

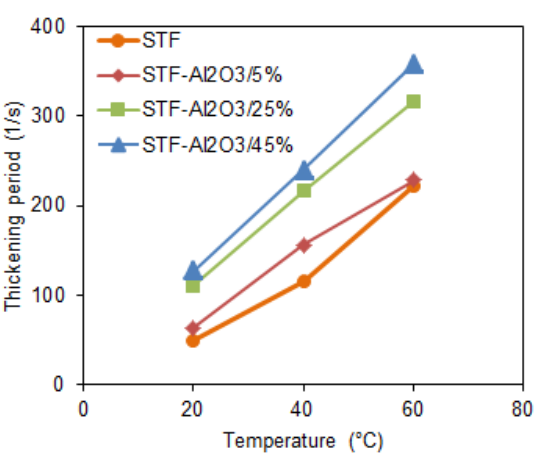

(b)

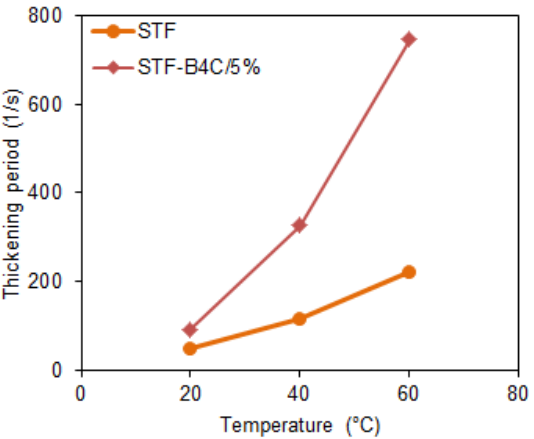

(c)

Figure 6. Thickening period of the STFs with (a) SiC, (b) $\mathrm{Al}_{2} \mathrm{O}_{3}$ and (c) $\mathrm{B}_{4} \mathrm{C}$ particles at various temperatures 


\subsection{Effects on thickening ratio}

Figure 7 shows the thickening ratio of the STFs with various additives and amounts at different temperatures. According to the results, the thickening ratio changes inversely with the temperature. It is known that hydrodynamic lubrication forces can easily overcome the inter-particle repulsive forces at lower temperatures, thereby readily triggering thickening. However, the thickening mechanism requires higher hydrodynamic lubrication forces due to increased repulsive forces at elevated temperatures, and therefore domination of the hydrodynamic lubrication forces decreases as the temperature increases, which ends up with a reduction in the thickening ratio. Alternatively, the thickening ratio drastically decreases as the amount of additives in the suspension increases. This trend stems from the disruptive influence of the additive particles on the hydro-clusters due to interstitial additives between the silica particles inside the STFs. There is a good match with the rheological results of Zhang et al. [31], [32] in that the thickening ratio is negatively affected by the amount of additives. In fact the thickening mechanism disappears after a limit loading of the additives, as stated by Zhang et al. [32]. It is possible to mention that this limit is exceeded at $\mathrm{B}_{4} \mathrm{C}$ loading of $25 \mathrm{wt} \%(14.24 \mathrm{vol} \%)$ for the STFs because the suspension could not exhibit thickening. However, the limit concentration of the additives for the STFs with $\mathrm{SiC}$ and $\mathrm{Al}_{2} \mathrm{O}_{3}$ particles is higher than $45 \mathrm{wt} \%$ because they keep their thickening behavior at $45 \mathrm{wt} \%$ of additive, which corresponds to loadings of $24.07 \mathrm{vol} \%$ and $20.51 \mathrm{vol} \%$ for $\mathrm{SiC}$ and $\mathrm{Al}_{2} \mathrm{O}_{3}$ respectively. When comparing these findings in terms of the volume fraction of the additives, STF is more susceptible to $\mathrm{B}_{4} \mathrm{C}$ particles because thickening disappears at lower volume fraction of $\mathrm{B}_{4} \mathrm{C}$ particles than the other additives. The graph shows that the thickening ratios of STFs with $5 \mathrm{wt} \%$ (2.53vol\%) $\mathrm{B}_{4} \mathrm{C}$ particles are very close to STFs with $45 \mathrm{wt} \%$ (24.07vol\% for $\mathrm{SiC}$ and $20.51 \mathrm{vol} \%$ for $\mathrm{Al}_{2} \mathrm{O}_{3}$ ), the other additives for each temperature level. However, the difference between $\mathrm{SiC}$ and $\mathrm{Al}_{2} \mathrm{O}_{3}$ is not notable in terms of the thickening ratio. In order to depict how the additives affect the thickening ratio, the rheological curves of the STFs with various additives are shown in Figure 8. 


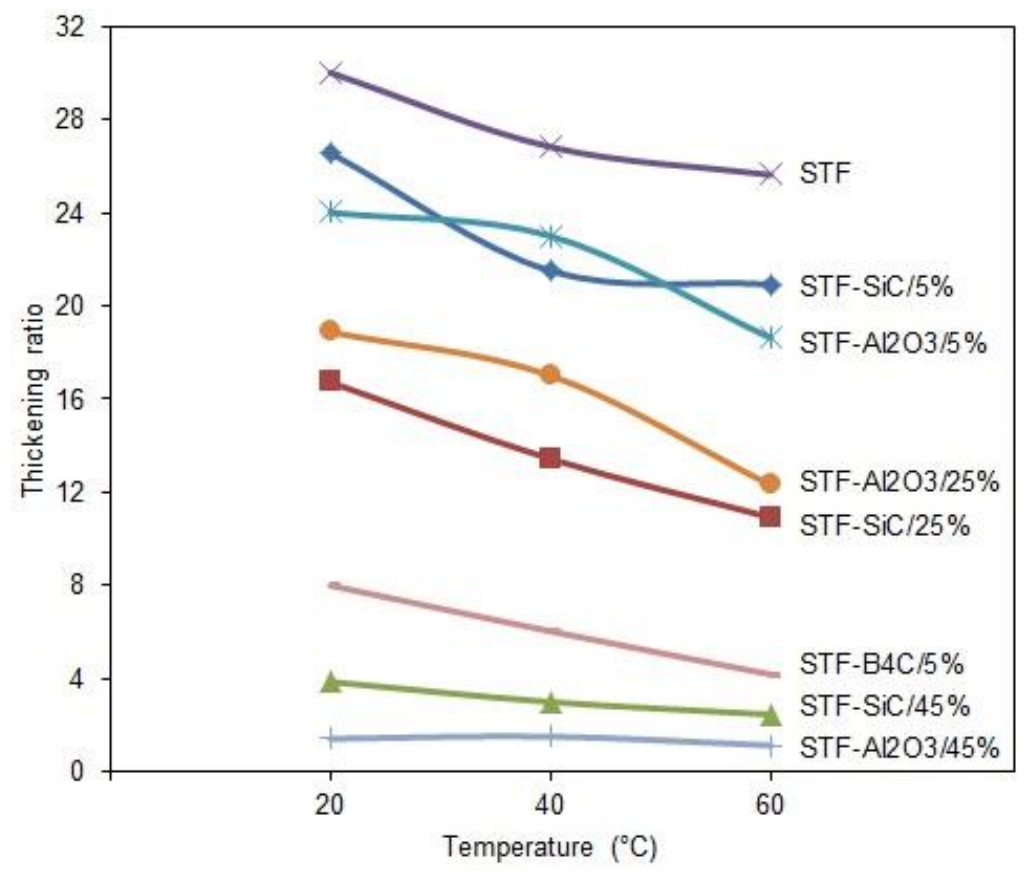

Figure 7. Thickening ratio of the STFs with various additive types and amounts at different temperatures

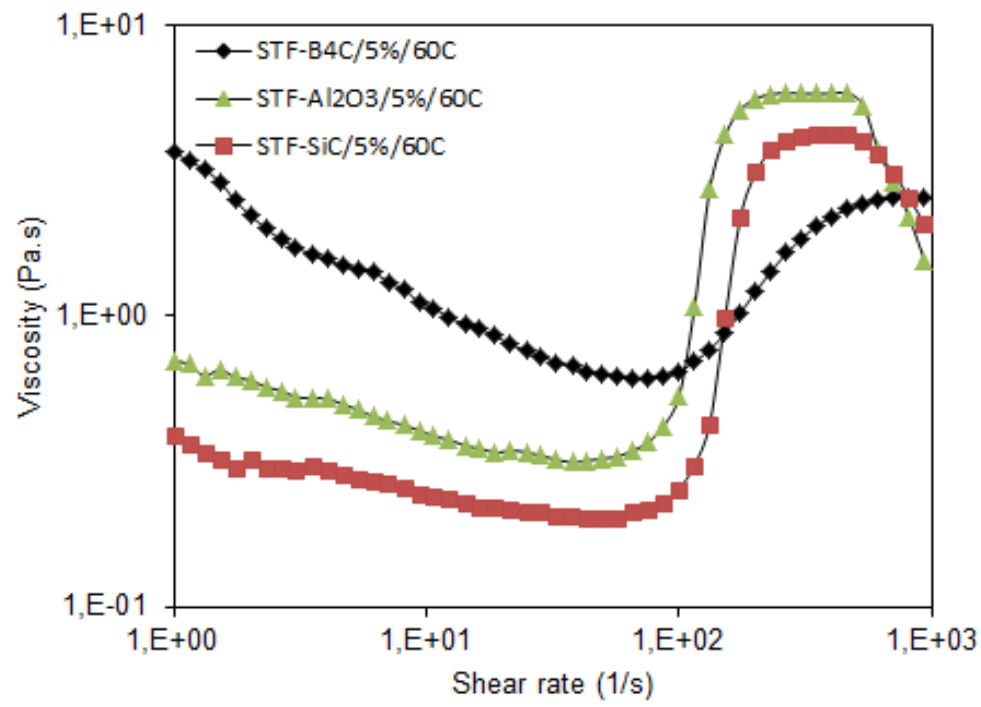

Figure 8. Rheological curves of the STFs with various additives at $60^{\circ} \mathrm{C}$

\section{Discussion}

This study investigated the effects of additive particles on the thickening behavior of STFs, while considering the viscosity profile, the critical shear rate, and the thickening period and thickening ratio. Three types of ceramic particles with close range particle size were used as particle additives in the suspensions, each of which had the same influences on the thickening mechanism of the STFs. Based on 
the rheological results, it is certain that the additive particles inside the STFs disrupted the thickening mechanism of the suspensions, but the intensity of this disruption varies depending on the parameters that varied in this study.

For the thickening mechanism of fumed silica and PEG 400 based STFs, the $\mathrm{B}_{4} \mathrm{C}$ particles were more destructive than the other additives; this can be verified by the rheological behavior of STFs with $\mathrm{B}_{4} \mathrm{C}$ loadings of $25 \mathrm{wt} \%(14.24 \mathrm{vol} \%)$ and $45 \mathrm{wt} \%(28.97 \mathrm{vol} \%)$ which only exhibited shear thinning at each temperature level. However, the suspensions with the other additives sustained their thickening behavior at additive loadings of $45 \mathrm{wt} \%$ (24.07vol\% for $\mathrm{SiC}$ and $20.51 \mathrm{vol} \%$ for $\mathrm{Al}_{2} \mathrm{O}_{3}$ ), even though the thickening mechanisms deteriorated. In fact, the volume fraction of silica comes into prominence at this point because adding the additive particles into the suspensions reduced the volume fraction of the silica which in turn reduce thickening. Figure 9 shows the volume fractions of the silica in the suspensions according to the corresponding weight fractions of the additives The graph indicates that a certain limit volume fraction of silica for suspensions with different additives to trigger thickening cannot be mentioned because the silica loadings in $\mathrm{SiC}$ and $\mathrm{Al}_{2} \mathrm{O}_{3}$ suspensions (8.6vol\% and 9.0vol\% respectively), which exhibited thickening, are lower than in the non-thickening $\mathrm{B}_{4} \mathrm{C}$ suspension $(9.8 \mathrm{vol} \%)$. This finding may stem from particle morphology of the additives interacting with the silica. Different shaped additive particles may cause variations in breaking the hydro-cluster networks. Fumed silica particles form a very complicated three dimensional cluster network due to the branched structure of the particles, unlike the spherical ones [42], but the additive particles are not shaped like the fumed silica where the additives did not contribute to the interactions between particles. It is known that the elongated or extended networks of the hydro-clusters are more effective in the thickening mechanism than the spherical aggregates [4], [42]. The micro-size additive particles occupy large spaces in the nano-size silica suspensions which stops the clusters from extending. Interactions between the silica particles are also influenced by the particle size of the additives. When reducing the particle size of the additives, the size of the obstacles inside the suspension approaches the silica particles, and therefore the extension of the clusters is not interrupted as much during thickening [46]. The big difference in particle size between the silica and the additives is where the micro-size additives stop the hydro-clusters from extending such that the clusters become more spherical than the clusters in pure STFs. 


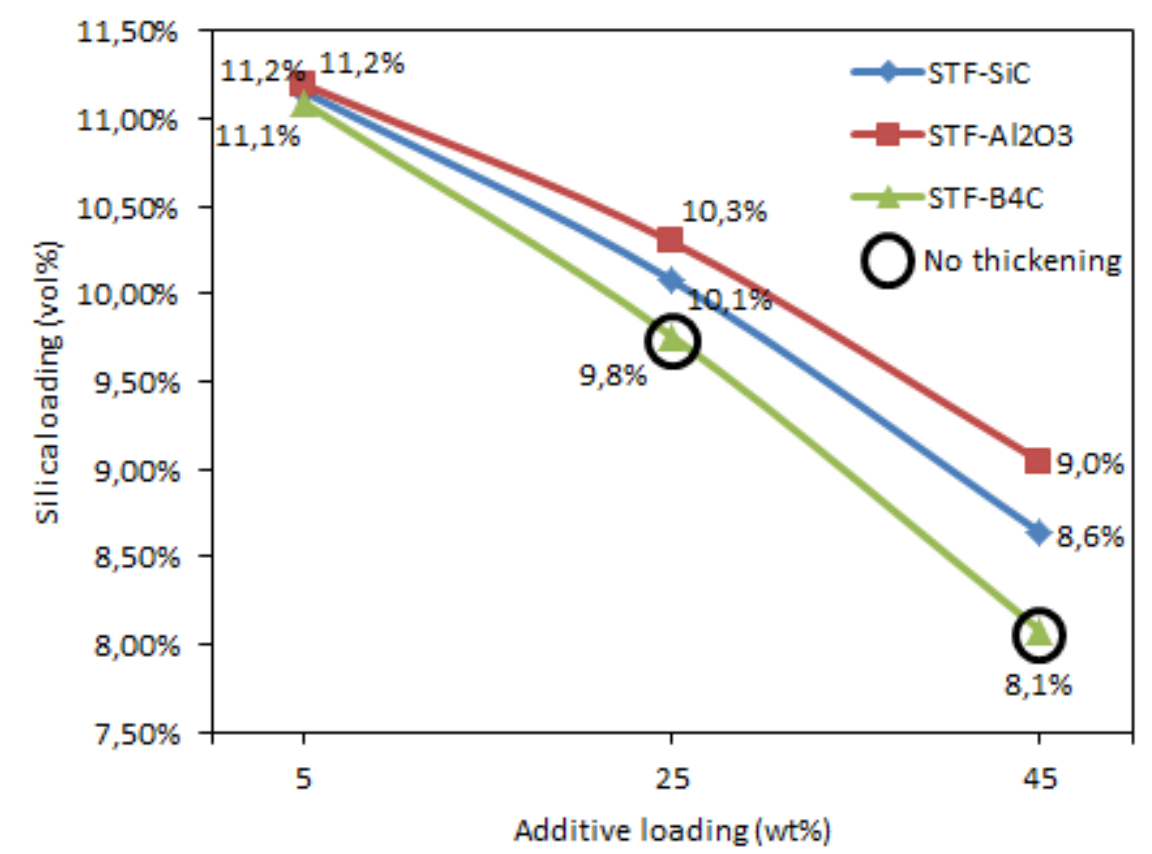

Figure 9. Volume fraction of the silica vs additive loading in the suspensions

As well as a purely hydro-clustering approach, the contribution of contact forces is suggested in recent studies [47]-[51]. Denn et al. [47], [48] stated that the hydro-clustering approach dominates the suspensions at low shear rates due to contactless rheology, but the contact forces are very effective for the jamming point where the particles contact each other at high shear rates. Beyond a critical point, contact forces generate force networks that dominate thickening where the hydrodynamic interactions are claimed to be insufficient. This trend increases as the shear rate increases [50]. Alternatively, particle loading plays an important role in contact rheology because the possibility of the contacted microstructure increases as the concentration of solid particles increases in the suspension. Dense suspensions provide more opportunity for the contact forces to increase, even at lower shear rates. It is suggested that mildly dense suspensions are dense enough for contact forces to develop during thickening [48]. Lin et al. [49] conducted shear reversal experiments to observe the relative contribution of hydrodynamic and contact forces in micro-size suspensions. The contact forces were said to be zero at the reversal stage of the experiments, while assuming that the microstructure remained unchanged and the hydrodynamic forces were identical in magnitude but reversed in direction. In view of this assumption, the qualitative difference between these forces was obtained to reveal the discrete contributions upon reversal. According to the results, contact forces are more dominant than hydrodynamic forces in the thickening stage of the suspension. Although shear reversal exhibits the effect of contact forces in the thickening mechanism, this model neglects the Brownian stresses which are inevitable for nano-size suspensions, especially with a lower concentration of solid particles.

In the light of the contact rheology model suggested in early studies [47]-[51], particle contacts are reduced due to interstitial additives between the silica particles, and therefore contact forces along the suspension decrease and the thickening behavior gradually decreases as the additive particles increase in the suspension. A schematic illustration of this process is shown in Figure 10. Non-contacted particles are drawn in gray lines joining the centres of the two involved particles, while the red lines depict the particles 
in contact during thickening. As Figure 10a shows, contacted particles develop contact networks that extend in the suspension, whereas the additive particles shown as black solids in Figure 10b, break the particle contacts and separate the contact networks into small branches.

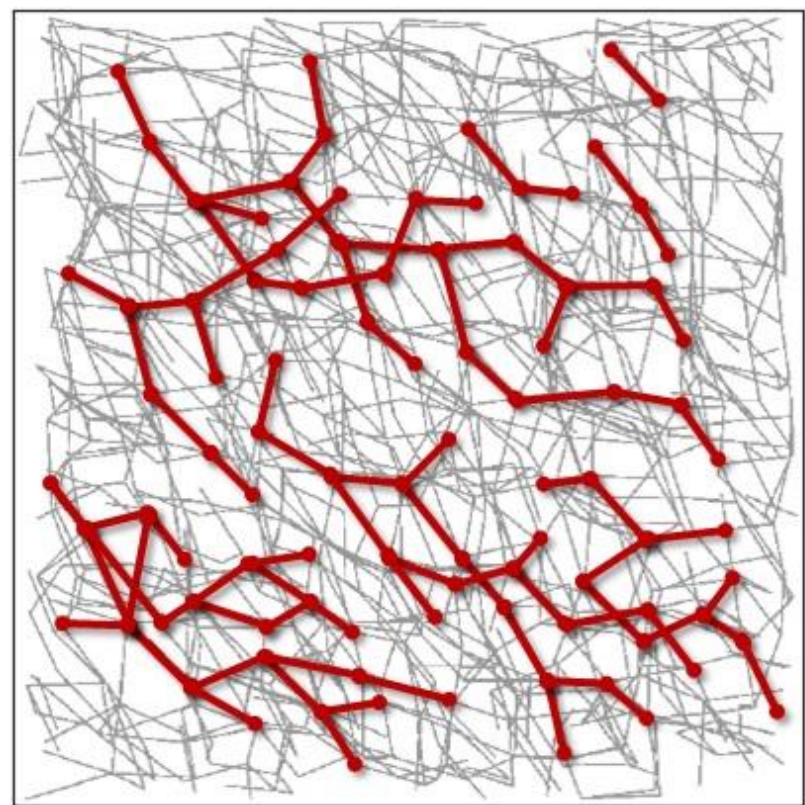

(a)

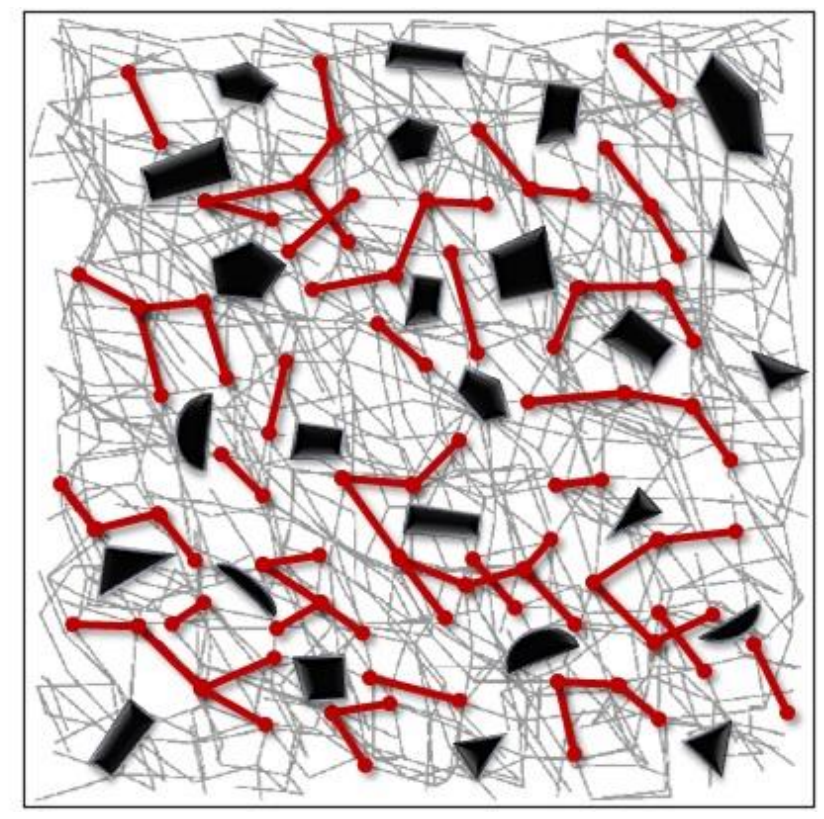

(b)

Figure 10. Particle contact networks for (a) pure STF and (b) STF with additives

\section{Conclusion}

In this study a novel approach for STFs was presented. Three different types of particles were used as additives in the STFs, and the rheological behavior of these suspensions was investigated. The thickening mechanism of these new fluids exhibited systematic variations with respect to different parameters. Additive particles provide an opportunity to modify the thickening stage of the STFs and thus the thickening mechanism can be controlled in various fields. These findings suggest that this approach could be useful for engineering applications where a higher viscosity profile and lower thickening ratios are required. Furthermore, additive particles can also be used to retard the activation of STFs by controlling their thickening period. Controllable fluid actuators can be main application area for these novel smart fluids.

\section{Acknowledgements}

The authors gratefully acknowledge the financial support by the Research Fund of Eskişehir Osmangazi University, Project \#ESOGU-BAP-2014-431. The author S.Gürgen also acknowledges the support of the Scientific and Technological Research Council of Turkey (TÜBİTAK) under Program 2214. 


\section{References}

[1] R. L. Hoffman, "Discontinuous and Dilatant Viscosity Behavior in Concentrated Suspensions. I. Observation of a Flow Instability," J. Rheol., vol. 16, no. 1, p. 155, 1972.

[2] N. J. Wagner and J. F. Brady, "Shear thickening in colloidal dispersions," Phys. Today, vol. 62, no. 10, pp. 27-32, Oct. 2009.

[3] B. J. Maranzano and N. J. Wagner, "Flow-small angle neutron scattering measurements of colloidal dispersion microstructure evolution through the shear thickening transition," J. Chem. Phys., vol. 117, no. 22, p. 10291, 2002.

[4] G. Bossis and J. F. Brady, "The rheology of Brownian suspensions," J. Chem. Phys., vol. 91, no. 3, p. 1866, 1989.

[5] W. H. Boersma, J. Laven, and H. N. Stein, "Viscoelastic properties of concentrated shear-thickening dispersions," J. Colloid Interface Sci., vol. 149, no. 1, pp. 10-22, Mar. 1992.

[6] L. E. Silbert, J. R. Melrose, and R. C. Ball, "A structural analysis of concentrated, aggregated colloids under flow," Mol. Phys., vol. 96, no. 11, pp. 1667-1675, Jun. 1999.

[7] A. A. Catherall, J. R. Melrose, and R. C. Ball, "Shear thickening and order-disorder effects in concentrated colloids at high shear rates," J. Rheol., vol. 44, no. 1, p. 1, 2000.

[8] R. S. Farr, J. R. Melrose, and R. C. Ball, "Kinetic theory of jamming in hard-sphere startup flows," Phys. Rev. E, vol. 55, no. 6, pp. 7203-7211, Jun. 1997.

[9] L. E. Gates Jr, "Evaluation and development of fluid armor systems," Air Force Materials Laboratory, vol. AFML-TR-68-362, 1968.

[10]J. L. Park, B. I. Yoon, J. G. Paik, and T. J. Kang, "Ballistic performance of p-aramid fabrics impregnated with shear thickening fluid; Part I - Effect of laminating sequence," Text. Res. J., vol. 82, no. 6, pp. 527-541, Apr. 2012.

[11]J. L. Park, B. I. Yoon, J. G. Paik, and T. J. Kang, "Ballistic performance of p-aramid fabrics impregnated with shear thickening fluid; Part II - Effect of fabric count and shot location," Text. Res. J., vol. 82, no. 6, pp. 542-557, Apr. 2012.

[12]A. Majumdar, B. S. Butola, and A. Srivastava, "Development of soft composite materials with improved impact resistance using Kevlar fabric and nano-silica based shear thickening fluid," Mater. Des., vol. 54, pp. 295-300, Feb. 2014.

[13]D. P. Kalman, R. L. Merrill, N. J. Wagner, and E. D. Wetzel, "Effect of Particle Hardness on the Penetration Behavior of Fabrics Intercalated with Dry Particles and Concentrated Particle-Fluid Suspensions," ACS Appl. Mater. Interfaces, vol. 1, no. 11, pp. 2602-2612, Nov. 2009.

[14]Y. Park, Y. Kim, A. H. Baluch, and C.-G. Kim, "Empirical study of the high velocity impact energy absorption characteristics of shear thickening fluid (STF) impregnated Kevlar fabric," Int. J. Impact Eng., vol. 72, pp. 67-74, Oct. 2014.

[15]A. Laha and A. Majumdar, "Interactive effects of p-aramid fabric structure and shear thickening fluid on impact resistance performance of soft armor materials," Mater. Des., vol. 89, pp. 286-293, Jan. 2016.

[16]V. B. C. Tan, T. E. Tay, and W. K. Teo, "Strengthening fabric armour with silica colloidal suspensions," Int. J. Solids Struct., vol. 42, no. 5-6, pp. 1561-1576, Mar. 2005.

[17]Y. S. Lee, E. D. Wetzel, and N. J. Wagner, "The ballistic impact characteristics of Kevlar ${ }^{\circledR}$ woven fabrics impregnated with a colloidal shear thickening fluid," Journal of Materials Science, vol. 38, no. 13, pp. 2825-2833, 2003.

[18]E. D. Wetzel, Y. S. Lee, R. G. Egres, K. M. Kirkwood, J. E. Kirkwood, and N. J. Wagner, "The effect of rheological parameters on the ballistic properties of shear thickening fluid (STF) Kevlar composites," presented at the Numiform, 2004. 
[19]A. Majumdar, B. S. Butola, and A. Srivastava, "An analysis of deformation and energy absorption modes of shear thickening fluid treated Kevlar fabrics as soft body armour materials," Mater. Des., vol. 51, pp. 148-153, Oct. 2013.

[20]A. Srivastava, A. Majumdar, and B. S. Butola, "Improving the impact resistance performance of Kevlar fabrics using silica based shear thickening fluid," Mater. Sci. Eng. A, vol. 529, pp. 224-229, Nov. 2011.

[21]M. R. Jolly and J. W. Bender, "Field responsive shear thickening fluid," US20060231357.

[22]K. Seshimo, "Viscoelastic damper," US4759428.

[23]X. Z. Zhang, W. H. Li, and X. L. Gong, "The rheology of shear thickening fluid (STF) and the dynamic performance of an STF-filled damper," Smart Mater. Struct., vol. 17, no. 3, p. 035027, Jun. 2008.

[24]C. Fischer, S. A. Braun, P.-E. Bourban, V. Michaud, C. J. G. Plummer, and J.-A. E. Månson, "Dynamic properties of sandwich structures with integrated shear-thickening fluids," Smart Mater. Struct., vol. 15, no. 5, pp. 1467-1475, Oct. 2006.

[25]H. M. Laun, "Rheology of extremely shear thickening polymer dispersionsa) (passively viscosity switching fluids)," J. Rheol., vol. 35, no. 6, p. 999, Aug. 1991.

[26] R. Helber, F. Doncker, and R. Bung, "Vibration attenuation by passive stiffness switching mounts," $J$. Sound Vib., vol. 138, no. 1, pp. 47-57, Apr. 1990.

[27]B. Chu, A. T. Brady, B. D. Mannhalter, and D. R. Salem, "Effect of silica particle surface chemistry on the shear thickening behaviour of concentrated colloidal suspensions," J. Phys. Appl. Phys., vol. 47, no. 33, p. 335302, Aug. 2014.

[28]I. Hunt, C. William, and C. H. Phelps, "Method to reduce movement of a CPF device via a shearthickening fluid," US4982792.

[29]T. H. Williams, J. Day, and P. Simon, "Surgical and Medical Garments and Materials Incorporating Shear Thickening Fluids," US2007000440086.

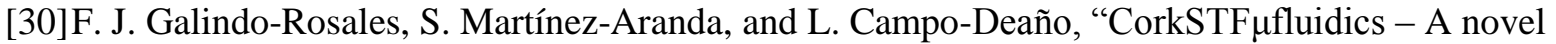
concept for the development of eco-friendly light-weight energy absorbing composites," Mater. Des., vol. 82, pp. 326-334, Oct. 2015.

[31]X. Zhang, W. Li, and X. Gong, "Thixotropy of MR shear-thickening fluids," Smart Mater. Struct., vol. 19, no. 12, p. 125012, Dec. 2010.

[32]X. Zhang, W. Li, and X. L. Gong, "Study on magnetorheological shear thickening fluid," Smart Mater. Struct., vol. 17, no. 1, p. 015051, Feb. 2008.

[33]W. Li, M. Nakano, T. Tian, A. Totsuka, and C. Sato, "Viscoelastic properties of MR shear thickening fluids," J. Fluid Sci. Technol., vol. 9, no. 2, pp. JFST0019-JFST0019, 2014.

[34] G. R. Peng, W. Li, T. F. Tian, J. Ding, and M. Nakano, "Experimental and modeling study of viscoelastic behaviors of magneto-rheological shear thickening fluids," Korea-Aust. Rheol. J., vol. 26, no. 2, pp. 149-158, May 2014.

[35]O. E. Petel, S. Ouellet, J. Loiseau, D. L. Frost, and A. J. Higgins, "A comparison of the ballistic performance of shear thickening fluids based on particle strength and volume fraction," Int. J. Impact Eng., vol. 85, pp. 83-96, Nov. 2015.

[36]O. E. Petel, S. Ouellet, J. Loiseau, B. J. Marr, D. L. Frost, and A. J. Higgins, "The effect of particle strength on the ballistic resistance of shear thickening fluids," Appl. Phys. Lett., vol. 102, no. 6, p. 064103, 2013.

[37]A. Srivastava, A. Majumdar, and B. S. Butola, "Improving the Impact Resistance of Textile Structures by using Shear Thickening Fluids: A Review," Crit. Rev. Solid State Mater. Sci., vol. 37, no. 2, pp. 115-129, Apr. 2012.

[38]M. Hasanzadeh and V. Mottaghitalab, "The Role of Shear-Thickening Fluids (STFs) in Ballistic and Stab-Resistance Improvement of Flexible Armor," J. Mater. Eng. Perform., vol. 23, no. 4, pp. 11821196, Apr. 2014. 
[39]D. M. Liu, "Particle packing and rheological property of highly-concentrated ceramic suspensions: $\varphi m$ determination and viscosity prediction," Journal of Materials Science, vol. 35, no. 21, pp. 5503$5507,2000$.

[40]C. T. Nguyen, F. Desgranges, G. Roy, N. Galanis, T. Maré, S. Boucher, and H. Angue Mintsa, "Temperature and particle-size dependent viscosity data for water-based nanofluids - Hysteresis phenomenon," Int. J. Heat Fluid Flow, vol. 28, no. 6, pp. 1492-1506, Dec. 2007.

[41]X.-Q. Liu, R.-Y. Bao, X.-J. Wu, W. Yang, B.-H. Xie, and M.-B. Yang, "Temperature induced gelation transition of a fumed silica/PEG shear thickening fluid," RSC Adv, vol. 5, no. 24, pp. 1836718374, 2015.

[42]S. R. Raghavan and S. A. Khan, "Shear-Thickening Response of Fumed Silica Suspensions under Steady and Oscillatory Shear," J. Colloid Interface Sci., vol. 185, no. 1, pp. 57-67, Jan. 1997.

[43] Y. J. Suh, M. Ullmann, S. K. Friedlander, and K. Y. Park, "Elastic Behavior of Nanoparticle Chain Aggregates (NCA): Effects of Substrate on NCA Stretching and First Observations by a High-Speed Camera ${ }^{\dagger}, "$ J. Phys. Chem. B, vol. 105, no. 47, pp. 11796-11799, Nov. 2001.

[44]T. J. Kang, C. Y. Kim, and K. H. Hong, "Rheological behavior of concentrated silica suspension and its application to soft armor," J. Appl. Polym. Sci., vol. 124, no. 2, pp. 1534-1541, Apr. 2012.

[45]H. A. Barnes, "Shear-Thickening ('Dilatancy') in Suspensions of Nonaggregating Solid Particles Dispersed in Newtonian Liquids," J. Rheol., vol. 33, no. 2, p. 329, 1999.

[46]S. Gürgen, M. C. Kuşhan, and W. Li, "The Effect of Carbide Particle Additives on Rheology of Shear Thickening Fluids," Korea-Australia Rheology Journal, vol. 28, no. 2, p. In-press, 2016.

[47]R. Seto, R. Mari, J. F. Morris, and M. M. Denn, "Discontinuous Shear Thickening of Frictional HardSphere Suspensions," Phys. Rev. Lett., vol. 111, no. 21, Nov. 2013.

[48]R. Mari, R. Seto, J. F. Morris, and M. M. Denn, "Shear thickening, frictionless and frictional rheologies in non-Brownian suspensions," J. Rheol., vol. 58, no. 6, pp. 1693-1724, Nov. 2014.

[49]N. Y. C. Lin, B. M. Guy, M. Hermes, C. Ness, J. Sun, W. C. K. Poon, and I. Cohen, "Hydrodynamic and Contact Contributions to Continuous Shear Thickening in Colloidal Suspensions," Phys. Rev. Lett., vol. 115, no. 22, Nov. 2015.

[50]I. R. Peters, S. Majumdar, and H. M. Jaeger, "Direct observation of dynamic shear jamming in dense suspensions," Nature, Apr. 2016.

[51]E. Brown and H. M. Jaeger, "The role of dilation and confining stresses in shear thickening of dense suspensions," J. Rheol., vol. 56, no. 4, p. 875, 2012. 